\title{
Sexual Dysfunction in Individuals with Alcohol Dependence Syndrome: a hospital based study
}

\author{
Tushar Saini ${ }^{1}$, Narayan R. Mutalik ${ }^{2}$ \\ ${ }^{1}$ Junior Resident, \\ ${ }^{2}$ Associate Professor, \\ Department of Psychiatry, S.N. Medical College, Bagalkot,
}

Corresponding author: Narayan Mutalik

Email - narayanmutalik@gmail.com

\begin{abstract}
Background: Alcohol and sexuality have been paired throughout history, poetry, and brief. It was reported that chronic, persistent and high amount of alcohol consumption results in sexual dysfunction which causes marked distress and affects the relationship of couple. There is lack of descriptive studies focusing on the sexual dysfunction of alcohol dependent individuals in India.

Methodology: Hundred in-patients who were diagnosed as alcohol dependence syndrome according to ICD-10 were assessed for severity of dependence using Severity of Alcohol Dependence Questionnaire (SADQ) and Assessment of sexual disorders was done using Arizona Sexual Experiences Scale (ASEX). Relationship between the severity of alcohol dependence and presence of sexual disorder is analyzed using chi-square, fisher's exact test and spearman's correlation coefficient test using SPSS software.

Results: Sixty seven percent of study participant had sexual dysfunction, among which forty four percent of participant have more than one type of sexual dysfunction. The most common sexual dysfunction being low sexual desire $(33 \%)$ followed by premature ejaculation $(28 \%)$ and erectile dysfunction (23\%). Sexual dysfunction was significantly associated with occupation and severity of alcohol dependence.

Conclusions: Sexual dysfunction is common in patients with alcohol dependence. This study focuses on the deleterious effect of alcohol on sexual functioning. Therefore, clinician needs to assess sexual dysfunction in all patients presenting with alcohol dependence and the data from the current study can be utilized in motivational interviewing of patients with alcohol dependence syndrome.
\end{abstract}

ABSTRACT

Keywords: Alcoholism, Alcohol dependence questionnaire, sexuality, low sexual desire, premature ejaculation.

(Paper received $-2^{\text {nd }}$ June 2020 , Peer review completed $-9^{\text {th }}$ July 2020, Accepted $-12^{\text {th }}$ July 2020)

\section{INTRODUCTION}

Proper sexual functioning provides a sense of psychological, physical, and social well-being and is one of the most important elements of quality of life [1]. Inability to respond to sexual stimulation or the experience of pain during the sexual act are essential features of sexual dysfunction. According to the 10th revision of the International Statistical Classification of Diseases and Related Health Problems (ICD- 10), sexual dysfunction refers to a person's inability "to participate in a sexual relationship as he or she would wish [2]. The various types of sexual dysfunction are decreased sexual desire, sexual aversion disorder, difficulty in erection, difficulty in achieving orgasm, premature ejaculation [3]. Sexual dysfunction disorder has an impact on quality of life and well-being of both males and females. The aetiology of sexual dysfunction is mainly multifactorial some factors such as chronic diseases, unhealthy life style, ageing, and medical treatments may increase the severity of the problem. Among unhealthy lifestyle habits, alcohol consumption 
and smoking are thought to be related with sexual dysfunction [4]. Alcohol abuse is the leading cause of impotence and other disturbances in sexual dysfunction [5]. Dissatisfaction in sexual life is often associated with anger, increased rates of marital violence, less warmth, and unity in relationships, breakups - all of which may in turn worsen the alcohol consumption [6]. Of the various mechanisms postulated to explain alcohol induced sexual dysfunction, some of them are inhibition of hypothalamic gonadotropin-releasing hormone and/ or pituitary luteinizing hormone [6-7], thereby altering the hypothalamo-pituitary-adrenal and the hypothalamo-pituitary-gonadal axis, reduction in plasma testosterone levels [8], increasing the inhibitory activity of gamma-amino butyric acid receptor and decreasing the excitatory activity of glutamate receptor in central nervous system (CNS) [9]. Psychological factors such as lack of arousability and disinterest in sex in partners - due to aversion, rejection, retaliation for her husband's undesirable drinking behaviour, and psychiatric co morbidities such as anxiety and depression as well as those induced by psychotropic medications. Because of under reporting by individuals consuming alcohol, the prevalence of alcohol induced sexual dysfunctions is unclear. Specially in the men who have chronic alcohol use, it have been reported that sexual dysfunction ranges from 8\%-95.2\% [10-18]. Some of the predictors of sexual dysfunction in alcoholics noted were advancing age, low educational level, unemployment, early age of onset of alcohol use, greater duration of alcohol dependence, concurrent tobacco use, greater quantity and frequency of drinking [18-19]. Various studies in Indian context have been conducted on sexual dysfunction due to alcohol consumption where a study found that out of 97 male inpatients admitted for treatment of alcoholism, $71 \%$ suffered from sexual dysfunction for a period of more than 12 months prior to admission to the hospital [12]. Pandey and others conducted a study on 50 alcohol dependent patients and matched controls. $68 \%$ of patient reported one or another sexual dysfunction [17]. Another study concluded that the prevalence of sexual dysfunction was $76 \%$. Impotence was most common diagnosis in $28 \%$ followed by loss of libido (26\%), delayed ejaculation(10\%), excessive libido(8\%) and premature ejaculation(4\%) [20]. A study failed to find any difference in sexual dysfunction in alcoholics abstinent for 2-3 months in comparison with a non-alcoholics group, speculating that alcohol-induced sexual was reversible with abstinence [19]. There are various studies that have glanced into sexual dysfunction due to use of alcohol but those reported from India are highly insufficient .To the best of our knowledge, studies which tried to find the prevalence of sexual dysfunction in male patient with alcohol dependence syndrome are scanty and in country like India where alcohol consumption is high, an insight into the matter of sexual dysfunction caused by alcohol can act as motivational factors to quit alcohol hence the present study was carried out. The aims of the current study were -

1. To find out the occurrence of sexual dysfunctions in male patients with alcohol dependence syndrome

2. To know the association between various socio-demographic factors and sexual dysfunction.

3. To assess the association between severity of alcohol dependence and sexual dysfunction.

\section{METHODOLOGY}

This prospective case series study was conducted among the patients with the history of alcohol dependence admitted in a tertiary care hospital at Bagalkot over a period of 6 months from October 2019 till March 2020. Sample size estimation was done using open epi software version 2.3.1 at 95\%confidence level according to a previous study [20]. At $20 \%$ relative precision, sample size estimated is 90 . Formula used to calculate sample size $=4 \mathrm{pq} / 1^{2}$.

\section{Inclusion criteria}

1. Patients with 21 years of age and above.

2. Patients who give informed consent.

3. Patient who fulfilled criteria for alcohol dependence or alcohol harmful use, according to ICD-10.

4. Patients who are married and have a regular sexual partner. 


\section{Exclusion criteria}

1. Patients who refuse to give informed consent.

2. Patients with history of primary sexual dysfunction prior to initiation of alcohol use.

3. Patients using other substance other than alcohol and tobacco (Cannabis, opioids, Benzodiazepines, Stimulants)

4. Patients with other medical conditions like diabetes mellitus, hypertension, signs and symptoms suggestive of alcoholic cirrhosis, a clinical diagnosis of endocrine disorders, other systemic illness, history of genitourinary surgery and neurological and spinal cord lesions.

5. Co-morbid psychiatric disorders: schizophrenia, delusional disorder, anxiety disorders and mood disorders including dysthymia.

6. Patients currently on medications affecting sexual function (antipsychotics, antidepressants, antihypertensive, steroid, disulfiram etc)

Ethical clearance was obtained from the Institute's Ethics Committee (Human Studies). Written informed consent in the local language was taken from all study subjects, before enrolment in the study. The nature and the purpose of the study were explained briefly to the study population in the informed consent form and then the study population was recruited according to inclusion-exclusion criteria as mentioned above. During the study period, all the recruits were given standardized self- answering questionnaires as mentioned below in the instruments used. ICD-10 F52 criteria were used to diagnose sexual dysfunction.

\section{Tools for assessment}

1. Semi-structured proforma: This is to elicit information on various socio-demographic details like age, education, occupation, religion, socioeconomic status, domicile, marital status etc., and various clinical details related to alcohol use, tobacco use and sexual dysfunction. Subtypes and severity were quantified using ASEX. Once the questionnaires were collected, the sample was subjected to statistical analysis.

2. Severity of Alcohol Dependence Questionnaire (SADQ): It is a 20-item clinical screening tool designed to measure the presence and level of alcohol dependence. Each item is scored on a 4-point scale giving a scoring range of 0 to 60.[21] It is divided into 5 sections like physical withdrawal symptoms, affective withdrawal symptoms, craving and relief drinking, typical daily consumption and reinstatement of dependence after period of abstinence. A score of $>31$ indicate severe alcohol dependence, 16-30 indicate moderate dependence, $<16$ indicate mild physical dependence [20].

3. Arizona Sexual Experience Scale (ASEX): It is a scale which is intended for assessment of sexual dysfunction in psychiatric patients and people with health problems. It particularly evaluates the modification and alteration of sexual functions in relation to the intake of medicines or psychotropic substances. This self-reported questionnaire can be both administered by a clinician and selfadministered. It is made up of 5 items rated on 6-point Likert scale. Each item explores a particular aspect of sexuality like sexual drive, arousal, penile erection, vaginal lubrication, ability to reach orgasm and satisfaction from orgasm. A total score $>19$ on ASEX or score $>5$ on any one item or a score $>4$ on any three items is associated with clinical sexual dysfunction [23].

\section{STATISTICAL ANALYSIS}

Data was collected and tabulated using Microsoft excel. Statistical analyses were performed using IBM SPSS Statistics for Windows (Trial Version 20.0). Frequency and percentages were calculated for all qualitative measures. Mean and the standard deviation was calculated for quantitative measures. Chi-square test and Fisher's exact test were used to analyse categorical values and check the association between two variables. A p-value of $<0.05$ is considered as statistically significant. 


\section{RESULTS}

The mean age of the study participants was 35 year ( $35 \pm 6.69$ years) with minimum and maximum age of 23 and 47 years respectively [Table-1]. Out of 100 participants in our study majority of them are from rural back ground (54\%). About $44 \%$ are educated up to $10^{\text {th }}$ standard.Most of the participants in the study are employed (97\%) out of all employed participants 38\% are skilled workers [Table-2]. About $42 \%$ of them belonging to middle class [Table-3]. All participants in the study are married and staying with spouse. It was found that $46 \%$ of the participants are referred by family members to our outpatient department.

In our study $67 \%$ of participants had started consuming alcohol for the first time during the age of 21-30 years. The mean age at first drink was 23 years with standard deviation of 4.49 ( $23 \pm 4.49$ years). The minimum and maximum age at first alcohol use was 17 and 39 years respectively. It was found that around $63 \%$ of participants have pattern of consuming similar amount of alcohol every day and were unable to abstain except due to unavailability because of no money. About $62 \%$ of all participants have severe alcohol dependence. The mean SADQ score of the study participants was 32.6 with standard deviation of 10.98 (32.6 \pm 10.98$)$. The minimum and maximum score of SADQ obtained from study participants in our study was 8 and 56 respectively.

About $92 \%$ of participants in our study group reported co morbid tobacco use with alcohol consumption. Out of which $85 \%$ have history of nicotine (tobacco) dependence. It was found that majority of the participants who have nicotine (tobacco) dependence have duration of dependence of 1-10 years (63\%). It was reported that mean duration of tobacco dependence was 6.5 years with standard deviation of 5.05 (6.5 \pm 5.05 years). In this study the minimum and maximum age of tobacco dependence in study participants were 0 and 21 years respectively. Around two third (67\%) of the study group reported having sexual dysfunction. Among which $23 \%$ of participants have only one type of sexual dysfunction and $44 \%$ of participants have more than one type of sexual dysfunction. The most common sexual dysfunction reported was low sexual desire present in one third (33\%) of participants, followed by premature ejaculation in $28 \%$ of participants. Erectile dysfunction is seen in $23 \%$ of participants among which $14 \%$ have difficulty in achieving erection and $9 \%$ have difficulty in maintaining erection.

Table-1 Socio-demographic profile and psychoactive substance related variables

\begin{tabular}{|c|c|}
\hline Socio-demographic variables & N (\%) \\
\hline Age (30-40 years) & $46 \%$ \\
\hline Education (10 ${ }^{\text {th }}$ standard) & $44 \%$ \\
\hline Occupation (skilled) & $38 \%$ \\
\hline Socio economic status (middle class) & $42 \%$ \\
\hline Domicile (rural) & $54 \%$ \\
\hline Alcohol related variables & $67 \%$ \\
\hline Age at first drink (21-30 years) & $63 \%$ \\
\hline Pattern of drinking (daily consumption of similar amount of alcohol) & \\
\hline SADQ scores & $62 \%$ \\
\hline Severe alcohol dependence & $29 \%$ \\
\hline Moderate alcohol dependence & $9 \%$ \\
\hline Mild alcohol dependence & \\
\hline Tobacco related variables & $92 \%$ \\
\hline History of tobacco use & $7 \%$ \\
\hline Harmful use of tobacco & $85 \%$ \\
\hline History of tobacco dependence & $63 \%$ \\
\hline Duration of tobacco dependence (1-10 years) &
\end{tabular}


A chi- square test was performed to examine association between occupation and sexual dysfunction. The association between these variables was significant, $\chi^{2}(7, N=100)=13.85, P=0.05$. Sexual dysfunction was found more in skilled workers than semiskilled and unskilled workers where as $88.88 \%$ of farmers reported significant sexual dysfunctions. Among alcohol related variable a chi-square test was performed to examine the association between severity of alcohol dependence and sexual dysfunction. The association between these variables was significant $\chi^{2}(2, N=100)=20.108, p<0.05$. Sexual dysfunction was found more in the participants with severe dependence than moderate dependence [Table-3] A significant positive association was found between variables like severity of alcohol dependence and sexual dysfunction. [Table-4]

Table-2 Distribution of sexual dysfunction in study participants

\begin{tabular}{|c|c|c|c|c|}
\hline \multirow{2}{*}{\multicolumn{2}{|c|}{ Type of sexual dysfunction }} & \multicolumn{2}{|c|}{ Sexual dysfunction } & \multirow[t]{2}{*}{$\mathbf{N}(\%)$} \\
\hline & & $\begin{array}{c}\text { Single } \\
\text { complaint }\end{array}$ & $\begin{array}{c}\text { With other sexual } \\
\text { dysfunctions }\end{array}$ & \\
\hline \multicolumn{2}{|c|}{ Low sexual desire } & $9 \%$ & $24 \%$ & $33 \%$ \\
\hline \multicolumn{2}{|c|}{ Premature ejaculation } & $2 \%$ & $26 \%$ & $28 \%$ \\
\hline \multirow[t]{2}{*}{$\begin{array}{c}\text { Erectile } \\
\text { dysfunction }\end{array}$} & $\begin{array}{l}\text { Difficulty in achieving } \\
\text { erection }\end{array}$ & $2 \%$ & $12 \%$ & $14 \%$ \\
\hline & $\begin{array}{l}\text { Difficulty in maintaining } \\
\text { erection }\end{array}$ & $1 \%$ & $8 \%$ & $9 \%$ \\
\hline \multicolumn{2}{|c|}{ Anorgasmia } & $0 \%$ & $18 \%$ & $18 \%$ \\
\hline \multicolumn{2}{|c|}{ Frequency dissatisfaction } & $0 \%$ & $15 \%$ & $15 \%$ \\
\hline \multicolumn{2}{|c|}{ Inhibited/delayed ejaculation } & $0 \%$ & $12 \%$ & $12 \%$ \\
\hline \multicolumn{2}{|c|}{ Dissatisfaction with own sexual functioning } & $5 \%$ & $6 \%$ & $11 \%$ \\
\hline \multicolumn{2}{|c|}{ Orgasm with flaccid penis } & $2 \%$ & $3 \%$ & $5 \%$ \\
\hline \multicolumn{2}{|c|}{$\begin{array}{c}\text { Dissatisfaction of sexual relationship with } \\
\text { partner }\end{array}$} & $5 \%$ & $6 \%$ & $11 \%$ \\
\hline \multicolumn{2}{|c|}{ Coital pain } & $1 \%$ & $1 \%$ & $2 \%$ \\
\hline
\end{tabular}

Table-3 Association of sexual dysfunction with alcohol related variable

\begin{tabular}{|c|c|c|c|}
\hline \multirow[t]{2}{*}{ Variables } & \multicolumn{2}{|c|}{ Sexual Dysfunction } & \multirow{2}{*}{$\begin{array}{l}\text { Chi Square Test } \\
\text { Significance }\end{array}$} \\
\hline & Absent & Present & \\
\hline \multicolumn{3}{|l|}{ Age at first drink } & \multirow{4}{*}{$\begin{array}{l}\chi^{2}=1.89 \\
P=0.38(\text { N.S })\end{array}$} \\
\hline Below 20 years & 8 & 20 & \\
\hline $21-30$ years & 22 & 45 & \\
\hline $31-40$ years & 3 & 2 & \\
\hline \multicolumn{3}{|c|}{ Severity of alcohol dependence } & \multirow{4}{*}{$\begin{array}{l}\chi^{2}=20.10 \\
P=0.00^{* *}\end{array}$} \\
\hline Mild dependence & 9 & 0 & \\
\hline Moderate dependence & 8 & 21 & \\
\hline Severe dependence & 16 & 46 & \\
\hline
\end{tabular}

${ }^{* *} \mathrm{p}<0.05$, N.S- Not significant

\section{DISCUSSION}

Man survives earthquakes, epidemics, the horrors of disease and all agonies of the soul, but for the all the time his most tormenting tragedy has been, is and will be tragedy of bedroom. Sex is one of the most unique aspects of life and is one of the most beautiful process of expressing desire, affection, trust and mutual 
warmth. Sexual dysfunction is a serious health problem that is recorded in the world more and more. Sexual dysfunction deteriorates the quality of life. It is reported in literature that among various risk factors chronic and persistent alcohol use is known to induce sexual dysfunction in males [24-27]. Alcohol increases the sexual urges by decreasing the inhibitions; at the same time it is found to cause impairment in the sexual function through various mechanisms such as vagal neuropathy which is seen in the individuals with high level of alcohol intake [28] and alteration in the levels of Gonadal hormones in individual with chronic alcohol use [29]. The mean age of participants was 35 years ( $35 \pm 6.69$ years). In a study conducted, mean age was approximately 35 years [15] whereas it was 39 years in other studies [30-31].

Majority of participants in our study had education up to $10^{\text {th }}$ standard (44\%). All most all participants were employed (97\%) out of which 37 were skilled workers which includes plumber, carpenter, welder, electrician, and drivers most of them are getting daily earnings which is an important risk factor for daily consumption of alcohol. Most of the participants in our study are from rural background (54\%) with 29\% and $17 \%$ are from semi urban and urban back ground respectively. In our study it was found that $42 \%$ of the participants belong to middle socioeconomic class with lower middle class and lower socioeconomic class being $37 \%$ and 19\% respectively. All the participants in the study are married (monogamous) staying with the spouse and have active sexual life. About $67 \%$ of participants started drinking alcohol for the first time during the age of $21-30$ years and $28 \%$ of the participants started drinking alcohol for the first time below the age of 20 years, whereas the study conducted by Prabhakaran and others, showed that $78 \%$ of participants of study group had their first alcohol consumption below the age of 20 years [30]. In our study it was found that around $63 \%$ of participants have pattern of consuming similar amount of alcohol every day and were unable to abstain except due to unavailability because of no money. About $26 \%$ of the individuals episodically consume alcohol with significant gaps in between where alcohol consumption was for 2 days without sobering up. Around $11 \%$ of participants consume alcohol infrequently whenever available. About $62 \%$ of participants in study group have severe alcohol dependence whereas $29 \%$ and $9 \%$ of the participants have moderate and mild alcohol dependence. Another study reported that $23 \%, 70 \%, 7 \%$ of participants were diagnosed to be having mild, moderate, and severe alcohol dependence respectively [32]. About $92 \%$ of participants in our study group reported co morbid tobacco use with alcohol consumption. Out of which $85 \%$ have history of nicotine (tobacco) dependence. It was found that majority of the participants who have nicotine (tobacco) dependence have duration of dependence of 1-10 years (63\%). Many similar studies have also included tobacco use because it was found to be most common co morbidity in alcohol dependent patients [15]. In our study sexual dysfunction was present in $67 \%$ of participants among which $23 \%$ of participants have only one type of sexual dysfunction and the most frequent complaint among them was low sexual desire which is reported in 9 participants. $44 \%$ of participants have more than one type of sexual dysfunction. The most common sexual dysfunction reported in our study group was low sexual desire which was present in $33 \%$ of the participants followed by premature ejaculation in $28 \%$ of study participants. Erectile dysfunction was reported in $23 \%$ of participants; of which $14 \%$ of them reported difficulty in achieving erection and $9 \%$ reported difficulty in maintain erection. Anorgasmia was reported in $18 \%$ of study participants which was followed by frequency dissatisfaction in 15\% participants. There is also a significant population which has psychogenic sexual dysfunction which is likely in a situation of marital conflict, which commonly occurs in the family of alcoholics [33], which was followed by inhibited or delayed ejaculation, dissatisfaction with own sexual functioning, and orgasm with flaccid penis in $12 \% 11 \%$ and $5 \%$ of study participants [Table-2]. As per the study by Aiswal and others, the prevalence of sexual dysfunction was $76 \%$. Impotence was most common diagnosis in $28 \%$ followed by loss of libido (26\%), delayed ejaculation $(10 \%)$, excessive libido (8\%), and premature ejaculation (4\%) [26]. Sexual dysfunction was present in the $72 \%$ of the study population as reported by previous study [15]. They have used sexual dysfunction checklist instead of ASEX scale which in fact, has more validity and reliability. Premature ejaculation was the major dysfunction, followed by low sexual desire and erectile dysfunction [15].

Among the various socio-demographic variables we could not find any association with sexual dysfunction except for the variable, occupation $(\mathrm{P}=0.05)$. Sexual dysfunction was found more in skilled workers than semiskilled and unskilled workers $(\mathrm{P}=0.05)$ probably because of their awareness and less stigmatizing 
Table 4: Association of Type of sexual dysfunction with severity of alcohol dependence

\begin{tabular}{|c|c|c|c|c|c|}
\hline \multirow[t]{2}{*}{ Type of sexual dysfunction } & \multicolumn{3}{|c|}{ Severity of alcohol dependence } & \multirow[t]{2}{*}{$\%$} & \multirow{2}{*}{$\begin{array}{c}\text { Test } \\
\text { significance }\end{array}$} \\
\hline & Mild & Moderate & Severe & & \\
\hline Low sexual desire & $0 \%$ & $6 \%$ & $27 \%$ & $33 \%$ & $\begin{array}{c}\chi^{2}=9.54 \\
p=0.008^{* *}\end{array}$ \\
\hline Difficulty in achieving erection & $0 \%$ & $3 \%$ & $11 \%$ & $14 \%$ & $\begin{array}{l}\chi^{2}=2.50 \\
p=0.285\end{array}$ \\
\hline Premature ejaculation & $0 \%$ & $3 \%$ & $25 \%$ & $28 \%$ & $\begin{array}{c}\chi^{2}=12.65 \\
p=0.002^{* *}\end{array}$ \\
\hline Frequency dissatisfaction & $0 \%$ & $3 \%$ & $12 \%$ & $15 \%$ & $\begin{array}{l}\chi^{2}=3.00 \\
p=0.223\end{array}$ \\
\hline $\begin{array}{c}\text { Dissatisfaction of sexual relation with } \\
\text { partner }\end{array}$ & $0 \%$ & $1 \%$ & $3 \%$ & $4 \%$ & $\begin{aligned} \chi^{2} & =0.512 \\
p & =0.774\end{aligned}$ \\
\hline Orgasm with flaccid penis & $0 \%$ & $2 \%$ & $3 \%$ & $5 \%$ & $\begin{array}{l}\chi^{2}=0.697 \\
p=0.706\end{array}$ \\
\hline $\begin{array}{l}\text { Dissatisfaction with own sexual } \\
\text { functions }\end{array}$ & $0 \%$ & $4 \%$ & $7 \%$ & $11 \%$ & $\begin{array}{l}\chi^{2}=1.349 \\
p=0.509\end{array}$ \\
\hline Anorgasmia & $0 \%$ & $3 \%$ & $15 \%$ & $18 \%$ & $\begin{array}{l}\chi^{2}=4.738 \\
p=0.094\end{array}$ \\
\hline Inhibited/delayed ejaculation & $0 \%$ & $1 \%$ & $11 \%$ & $12 \%$ & $\begin{array}{l}\chi^{2}=5.171 \\
p=0.075\end{array}$ \\
\hline Difficulty in maintain erection & $0 \%$ & $3 \%$ & $6 \%$ & $9 \%$ & $\begin{array}{l}\chi^{2}=0.989 \\
p=0.610\end{array}$ \\
\hline Coital pain & $0 \%$ & $2 \%$ & $0 \%$ & $2 \%$ & $\begin{array}{l}\chi^{2}=4.996 \\
p=0.082\end{array}$ \\
\hline
\end{tabular}

attitude toward disclosing about sexual matters might have reported more freely regarding their sexual dysfunction. Whereas $88.88 \%$ of farmers reported significant sexual dysfunctions. In our study sexual dysfunction had a significant association with the severity of alcohol dependence $(\mathrm{P}=0.00)$. About $62 \%$ of all participants have severe alcohol dependence. This finding was different from study conducted in which no significant association was found with factors such as age at first drink, pattern of drinking or with family history of alcohol use [15]. It was reported that there was no significant association found between sexual dysfunction and pattern of drinking and age at first drink in this study. In a pilot study conducted by Mandell and Miller various factors such as quantity, frequency and duration of drinking, from onset of regular drinking to present, were related to sexual dysfunction. In chronic alcoholics the duration of dependence increases which result in combined effect of alcohol on various systems like CNS, hepatic, endocrinal, and gonadal systems thus resulting in greater severity of sexual dysfunction [26].

It has been reported in many studies that nicotine use was significant determinant of sexual dysfunctions [34-35] but in our study there is no significant association was found between sexual dysfunction and tobacco related variables namely history of and duration of tobacco dependence. This might be due to shorter duration of tobacco dependence among study participants in our study. Further studies need to use standardized scales for assessing tobacco dependence in order to avoid this error. In a study on the prevalence of sexual dysfunction and potential risk factors that impairs sexual dysfunction in the Turkish females, it was reported that patient with or without sexual dysfunction had no significant differences in their smoking history. It was found in our study that there was a significant positive correlation of sexual dysfunction with severity of alcohol dependence. This finding agrees with the earlier studies [15-16, 37]. The positive correlation may be explained by greater neurotoxic effects, actions on the gonadal hormones and 
reversible vagal neuropathy which occurs in chronic alcoholics. There was no significant correlation was found between age at first drink and sexual dysfunction. Sexual dysfunction is of greater relevance in the patients of alcohol dependence syndrome which results in treatment non adherence and sexual or marital disharmony and is common contributor of relapses. Due to limited research work in this area, sexual dysfunctions in alcohol dependence patients are often neglected and unexplored in routine clinical practice.

\section{Limitations}

The main limitation of this study is that it is a hospital-based cross-sectional study. This study being conducted among patients admitted for de-addiction in a tertiary care and sample size in our study was less. The study also represents only a small population of the society so generalized results for a population cannot be interpreted through the study. Case series nature of our study shows association rather than causality. Our study sample had co-morbid tobacco use in about ninety-two percent of individuals which could not be excluded.

\section{CONCLUSIONS}

Sexual dysfunction is common among the male patients with alcohol dependence syndrome. The most common sexual dysfunction being low sexual desire (33\%) followed by premature ejaculation (28\%) and erectile dysfunction (23\%). Our study highlights the hazardous effects of alcohol on the sexual functioning, and this knowledge can be used while explaining medical model during motivational interviewing and motivational enhancement therapy session of patients with alcohol dependence syndrome by a consultant psychiatrist. The results obtained from this study will be implicated in terms of awareness creation, improvising de-addiction services, training and further research on this population with alcohol dependence syndrome and their spouses and partners. This may be extended to patients with other psychoactive substance dependence also, thereby bringing out their cumulative effects. Furthermore, it has provided us a platform for understanding the requirement for comprehensive, feasible, psychosocial/sexual services for the patient with alcohol dependence syndrome having sexual dysfunction. Moreover, the current study also highlights the need for regular assessment of sexual dysfunction in patients of alcohol dependence syndrome. Similar studies can be done in the rural and urban areas considering the female gender, as well as at the community levels. Sensitization programmes at school and colleges highlighting this aspect as well as interventional programs and treatment effectiveness studies, comparing the various methods to treat alcohol induced sexual dysfunction, can be tried.

\section{REFERENCES}

1. Bancroft J, editor. Sexual problems. In: Human Sexuality and Its Problems.2nd ed. New York: Churchill Livingstone; 1983. p. 360-411

2. Human Sexuality and Sexual Dysfunctions. In: Pataki CS, Sussman N, editors. Kaplan \& Sadock's Synopsis of Psychiatry Behavioral Sciences/Clinical Psychiatry. 11th ed. Philadelphia : Wolters Kluwer; 2015. p. 575.

3. American Psychiatric Association: Diagnostic and Statistical Manual, 4th ed. American Psychiatric Association: Washington DC; 1994.

4. Austoni E, Mirone V, Parazzini F, Fasolo CB, Turchi P, Pescatoi ES, Ricci E, Gentile V. Smoking as a risk factor forerectile dysfunction: Data from the Andrology Prevention Weeks 2001-2002. A study of the Italian Society of Andrology. Eur Urol 2005;48:810-8.

5. Mendelson JH, Mello NK. Medical progress, Biologic concomitants of Alcoholism. N Engl J Med 1979;301:912-21.

6. Heinz A, Rommelspacher H, Gräf KJ, Kürten I, Otto M, Baumgartner A, et al. .Hypothalamic-pituitary-gonadal axis, prolactin, and cortisol in alcoholics during withdrawal and after three weeks of abstinence: Comparison with healthy control subjects. Psychiatry Res 1995;56:81-95.

7. Hiney JK, Dees WL. Ethanol inhibits luteinizing hormone-releasing hormone release from the median eminence of prepubertal female rats in vitro: Investigation of its actions on norepinephrine and prostaglandin-E2. Endocrinology 1991;128:1404-8.

8. Gordon GG, Altman K, Southren AL, Rubin E, Lieber CS. Effect of alcohol (ethanol) administration on sex-hormone metabolism in normal men. N Engl J Med 1976;295:793-7. 
9. Fernandes A, De Sousa A. Alcohol dependence and sexual dysfunction: A clinical review. Paripex Indian J Res 2014;3:187-90.

10. Lemere F, Smith JW. Alcohol-induced sexual impotence. Am J Psychiatry 1973;130:212-3.

11. Dişsiz M, Oskay ÜY. Evaluation of sexual functions in Turkish alcohol-dependent males. J Sex Med 2011;8:3181-7.

12. Vijayasenan ME. Alcohol and sex. N Z Med J 1981;93:18-20.

13. Jensen SB. Sexual customs and dysfunction in alcoholics: Part I. Br J Sex Med 1979;6:29-32.

14. Whalley LJ. Sexual adjustment of male alcoholics. Acta Psychiatr Scand 1978;58:281-98.

15. Arackal BS, Benegal V. Prevalence of sexual dysfunction in male subjects with alcohol dependence. Indian J Psychiatry 2007;49:109-12.

16. Dachille G, Lamuraglia M, Leone M, Pagliarulo A, Palasciano G, Salerno MT, et al. Erectile dysfunction and alcohol intake. Urologia 2008;75:170-6.

17. Pandey AK, Sapkota N, Tambi A, Shyangwa PM. Clinico-demographic profile, sexual dysfunction and readiness to change in male alcohol dependence syndrome inpatients in a tertiary hospital. Nepal Med Coll J 2012; $14: 35-40$.

18. Grover S, Mattoo SK, Pendharkar S, Kandappan V. Sexual dysfunction in patients with alcohol and opioid dependence. Indian J Psychol Med 2014;36:355-65.

19. Schiavi RC, Stimmel BB, Mandeli J, White D. Chronic alcoholism and male sexual function. Am J Psychiatry $1995 ; 152: 1045-51$.

20. Aswal S, Verma KK, Mathur A, Singh H, Jain L, Kapur T. Study of psychiatric morbidity and psychosexual dysfunctions in patients of alcohol dependence. Delhi Psychiatry J 2012;15:379-84.

21. Stockwell T, Murphy D \& Hodgson R. The severity of alcohol depend ence questionnaire: Its use, reliability and validity. Br J Addiction 1983;78(2):45-156.

22. Raistrick, D, Heather N \& Godfrey C. Review of the Effectiveness of Treatment for Alcohol Problems. National Treatment Agency for Substance Misuse, London pg 71.

23. McGahuey CA, Gelenberg AJ, Laukes CA, Moreno FA, Delgado PL, McKnight KM, Manber R. The Arizona Sexual Experience Scale (ASEX): reliability and validity. J Sex Marital Ther 2000;26(1):30-6

24. Can S. Erectile dysfunction in men with alcohol dependence, comorbidity relate to other axis I. disorders. Ph.D.diss [MS thesis], Bakirkoy Resesarch and Training Hospital for Psychiatry, Neurology and Neurosurgery, I'stanbul, 2002.

25. Martin-Morales A, Sanchez-Cruz JJ, Saenz de Tejada I, Rodriguez-Vela L, Jimenez-Cruz JF, BurgosRodriguez R. Prevalence and independent risk factors for erectile dysfunction in Spain: results of the Epidemiologia de la Disfuncion erectile masculina study. J Urol 2001;166:569-74.

26. Mandell W, Miller CM. Male sexual dysfunction as related to alcohol consumption: A pilot study. Alcohol Clin Exp Res 1983;7:65-9.

27. O'Farrel TJ, Kleinke CL, Cutter HS. Sexual adjustment of male alcoholics: Changes from before to after receiving alcoholism counseling with and without marital therapy. Addict Behav 1998;23:419-25.

28. Villanta J, Estruch R, Antunex E, Valls J. Vagal Neuropathy in Chronic Alcoholics: Relation to Ethanol consumption. Alcohol Alcohol 1989:24421-8.

29. Gumus B, Yigitoglu MR, Lekili M, Vyanik BS. Effect of longterm alcohol abuse on male sexual function and serum gonadal harmone levels. Intl Uro Nephrol 1998;30:755-9.

30. Prabhakaran DK, Nisha A, Varghese PJ. Prevalence and correlates of sexual dysfunction in male patients with alcohol dependence syndrome: A cross-sectional study. Indian J Psychiatry 2018;60:71-7.

31. Saha A. Prevalence of sexual dysfunction in cases of alcohol dependence syndrome. Int $\mathrm{J}$ Adv Med 2015;2:110-9.

32. Pavan K, Chada Apurva, Anaveni R, Roy S. Study of prevalence of Sexual dysfunction in Alcohol Dependant individuals: A cross sectional study. Perspectives in medical research 2017;5(1):25-29.

33. Van Thiel DH, Gavaler JS, Sanghvi A. Recovery of sexual function in abstinent alcoholic men. Gastroenterol 1983;84:677-82.

34. Lam TH, Abdullah AS, Ho LM, Yip AW, Fan S. Smoking and sexual dysfunction in Chinese males: Findings from men's health survey. Int J Impot Res 2006;18:364-9.

35. Feldman HA, Goldstein I, Hatzichristou DG, Krane RJ, McKinlay JB.Impotence and its medical and psychosocial correlates: Results of the Massachusetts male aging study. J Urol 1994;151:54-61.

36. Cayan S, Akbay E, Bozlu M, Canpolat B, Acar D, Ulusoy E, et al. The prevalence of female sexual dysfunction and potential risk factors that may impair sexual function in Turkish women. Urol Int 2004;72:52-7.

37. Lee AC, Ho LM, Yip AW, Fan S, Lam TH. The effect of alcohol drinking on erectile dysfunction in Chinese men. Int J Impot Res 2010;22:272-8.

$* * * * * * * * * * * * * * * * * * * * * * * * * * * * * * * * * * * *$

Acknowledgements - We would like to thank all the patients who became the part of the study and our hospital authorities for permitting to conduct this study.

Conflict of Interest - Nil; Funding - Intramural 